\title{
Rapid compensatory changes in the expression of EAAT- 3 and GAT- 1 transporters during seizures in cells of the CA1 and dentate gyrus
}

\author{
Laura Medina-Ceja*, Flavio Sandoval-García, Alberto Morales-Villagrán and Silvia J López-Pérez
}

\begin{abstract}
Background: Epilepsy is a neurological disorder produced by an imbalance between excitatory and inhibitory neurotransmission, in which transporters of both glutamate and GABA have been implicated. Hence, at different times after local administration of the convulsive drug 4-aminopyridine (4-AP) we analyzed the expression of EAAT-3 and GAT-1 transporter proteins in cells of the CA1 and dentate gyrus.
\end{abstract}

Methods: Dual immunofluorescence was used to detect the co-localization of transporters and a neuronal marker. In parallel, EEG recordings were performed and convulsive behavior was rated using a modified Racine Scale.

Results: By 60 min after 4-AP injection, EAAT-3/NeuN co-labelling had increased in dentate granule cells and decreased in CA1 pyramidal cells. In the latter, this decrease persisted for up to 180 min after 4-AP administration. In both the DG and CA1, the number of GAT-1 labeled cells increased 60 min after 4-AP administration, although by 180 min GAT-1 labeled cells decreased in the DG alone. The increase in EAAT-3/NeuN colabelling in DG was correlated with maximum epileptiform activity and convulsive behavior.

Conclusions: These findings suggest that a compensatory mechanism exists to protect against acute seizures induced by 4-AP, whereby EAAT-3/NeuN cells is rapidly up regulated in order to enhance the removal of glutamate from the extrasynaptic space, and attenuating seizure activity.

Keywords: 4-Aminopyridine, EAAT-3, GAT-1, Hippocampus, Immunofluorescence, Seizures

\section{Background}

Epilepsy is a neurological disease with a lifetime prevalence of $2-5 \%$ (excluding febrile seizures), affecting approximately 67 million people worldwide [1]. Epilepsy is thought to reflect an imbalance between excitatory and inhibitory neurotransmission $[2,3]$ and indeed increased levels of glutamate, the principal excitatory neurotransmitter in the central nervous system (CNS), have been well documented during seizures $[2,4]$. This excess glutamate must be removed from the synaptic space by membrane proteins called transporters. At least five subtypes of glutamate transporters have been described, along with several variants: GLAST (EAAT-1), GLT-1 (EAAT-2, EAAT-2a, EAAT-2b and EAAT-2c), EAAC-1(EAAT-3), EAAT-4 and EAAT-5 [5-7]. Glutamate transporters are

\footnotetext{
* Correspondence: Imedina@cucba.udg.mx

Laboratorio de Neurofisiología y Neuroquímica, Departamento de Biología Celular y Molecular, Centro Universitario de Ciencias Biológicas y

Agropecuarias, Universidad de Guadalajara, Km. 15.5 Carretera GuadalajaraNogales Predio "Las Agujas"; Nextipac, Zapopan, Jalisco CP 45110, Mexico
}

expressed by neurons and glial cells in many regions of the brain and for example, the EAAT-3 transporter is expressed in the dendrites and soma of granule and pyramidal cells of the hippocampal dentate gyrus and CA1 region, respectively. Moreover, EAAT-3 transporters are found at both asymmetric and symmetric synapses [8-10]. In conjunction with the cysteine/glutamate antiporter $\mathrm{X}_{\mathrm{C}}^{-}$EAAT-3 protects neuronal HT22 cells (an immortalized hippocampal cell line) from oxidative glutamate toxicity [11]. Indeed, altered EAAT-3 expression has been described in epilepsy and in response to particular seizure types. Accordingly, in a pilocarpine-induced rat model of Temporal Lobe Epilepsy (TLE), EAAT-3 gene and protein expression increases rapidly in dentate granule cells in association with long-lasting epilepsy [12]. Similar findings have been reported in TLE patients [13-15], in whom an increase in EAAT-3 protein levels and in the percentage of EAAT-3-IR neurons occurs in CA2 and in the granule cell layer of the dentate gyrus. 
GABA (gamma-aminobutyric acid), the principal inhibitory neurotransmitter, is also thought to play an important role in epilepsy and four GABA transporter subtypes have been identified in mammals: GAT-1, GAT-2, GAT-3 and GAT-4 [16]. In particular, GAT-1 is expressed in the pyramidal and granule cell layers of the hippocampal formation, and this transporter is considered therapeutically significant given the antiepileptic effects elicited by its blockade $[17,18]$. Changes in GAT-1 protein and mRNA expression have also been described in various epilepsy models, including the kainic acid, picrotoxin, $\mathrm{FeCl}_{2}$ models, and in TLE patients [13,19-21].

Here we have studied the changes in EAAT-3 and GAT1 transporter protein expression in hippocampal cells of the dentate gyrus (DG) and CA1 at different times after 4aminopyridine (4-AP) administration because it was demonstrated that 4-AP increases the levels of glutamate and GABA in the hippocampal extracellular space, as well as glutamate produces hyperactivation of its receptors and seizures [2,3,22]. Although, participation of glutamate and GABA transporters in seizures is well documented, there is no evidence about their contribution in this model of seizures considering their possible effect in extracellular neurotransmitters levels observed previously and relation with EEG activity as well as convulsive behavior. For this reason, we used dual immunofluorescence to determine whether glutamate or GABA transporters co-localize with the neuronal marker NeuN. In parallel, we recorded EEG activity and analyzed seizure behavior using a modified version of the Racine Scale [23] to investigate the correlation between seizure intensity and changes in EAAT-3/Neun or GAT-1/ Neun co-labeled cells. In addition, we chose the entorhinal cortex (EC) in order to inject 4-AP because it produces an epileptiform pattern in EEG recordings previously studied in our laboratory $[2,23,24]$. Our results show a rapid compensatory effect in the average number of cells immunolabelled for EAAT-3 during maximum epileptiform activity associated with a high convulsive behavior in bilateral DG region. We conclude that this compensatory mechanism has the purpose to increase glutamate clearance from the extrasynaptic space due to the raise in glutamate levels induced by $\mathrm{K}^{+}$channel blocked effect of 4-AP. Also, increases in GAT-1/Neun labeled DG cells observed may facilitate increased GABA release in this region via reverse transport, in order to enhance inhibitory effect in response to the excitatory stimuli produced by seizures and the effect of glutamate exposure in 4-AP treated rats, but it is necessary additional experimental work to confirm this hypothesis.

\section{Methods}

\section{Animal surgery}

Twenty-four adult male Wistar rats (250-350 g in weight) were used in the present study. All experimental procedures were designed in order to minimize animal suffering and the total number of animals used. All rats were maintained in individual cages in a temperature-controlled room, on a 12-h light/dark cycle with ad libitum access to food and water. This protocol was conformed to the Rules for Research in Health Matters (Mexican Official Norms NOM-062-ZOO1999, NOM-033-ZOO-1995) and it was approved by the local Animal Care Committee.

Rats were first anesthetized with isofluorane in $100 \% \mathrm{O}_{2}$ and secured in a Stoelting stereotaxic frame with the incisor bar positioned at $-3.3 \mathrm{~mm}$. A stainless steel guide cannula (0.5 mm internal diameter) was implanted into each rat through a hole drilled in the skull, and it was positioned in the right entorhinal cortex (rEC) at the following stereotaxic coordinates relative to bregma (rEC: AP $-8 \mathrm{~mm}, \mathrm{~L} 4.6 \mathrm{~mm}$, $\mathrm{V} 4 \mathrm{~mm}$ ). This cannula was used to insert an injection needle (V $5 \mathrm{~mm}$ ) that also served as a recording electrode. The cannula was insulated by varnishing the entire surface except a $1 \mathrm{~mm}$ portion of its tip. Four stainless steel screws were attached to the skull, two above bregma and two above the cerebellum, which served as indifferent and ground electrodes, respectively. Three surface electrodes with the same characteristics as the electrodes described above were implanted into the skull above: the left occipital cortex binocular (lOCB, AP $-8 \mathrm{~mm}, \mathrm{~L}-4.6 \mathrm{~mm}$ relative to bregma); and the right and left occipital cortex (rOC/lOC, AP $-5.6 \mathrm{~mm}$, L $5.0 \mathrm{~mm}$; AP $-5.6 \mathrm{~mm}, \mathrm{~L}-5 \mathrm{~m}$ relative to bregma). The guide cannula and surface electrode wires were attached to a socket connector and fixed to the skull with acrylic dental cement.

\section{Drug administration and EEG recording}

After surgery, the animals were allowed to recover for $24 \mathrm{~h}$ and they were then divided into experimental groups as follows: 3 control groups ( $\mathrm{n}=3$ per group) received an injection of the vehicle alone $(\mathrm{NaCl}, 0.9 \%)$ and 30,60 or $180 \mathrm{~min}$ after injection the animals were sacrificed; 3 experimental groups of animals ( $\mathrm{n}=5$ per group) were injected with 10 nmols 4-AP, and sacrificed similarly 30, 60 or $180 \mathrm{~min}$ after injection.

4-AP (Sigma St. Louis, MO, USA) was diluted in the appropriate concentration of $\mathrm{NaCl}$ to maintain iso-osmolarity. Both vehicle and 4-AP solutions were injected locally into the $\mathrm{rEC}$ at a flow rate of $0.5 \mu \mathrm{l} / \mathrm{min}$ for $2 \mathrm{~min}$ (final volume $1 \mu \mathrm{l}$ ) using a microsyringe mounted on a BAS microinjection pump.

The rats were placed in a container unit and the electrodes connected to a cable fixed to a balanced arm. EEG activity was recorded using a Grass polygraph model 6 with a low-frequency filter at $1 \mathrm{~Hz}$ and a high frequency filter at $300 \mathrm{~Hz}$, and it was sampled at $100 \mathrm{~Hz} /$ channel (four channels). Data was stored on a computer hard disk and analyzed with AcqKnowledge software from Biopac Systems MP150 (Biopac Systems, Inc. Goleta, CA, USA). After 
recording basal activity for $30 \mathrm{~min}$, vehicle or 4-AP (10 nmol) was administered and the animals were then observed continuously for 30, 60 or $180 \mathrm{~min}$, during which time EEG activity was recorded. The basal electrical activity of each group was analyzed, and the amplitude and frequency averaged over a $5 \mathrm{~min}$ recording period. The data from the experimental groups was analyzed by measuring the amplitude of single epileptiform discharges over a 5 min period of the recording at different times after drug administration. The frequency of the EEG epileptiform activity (the number of single epileptiform discharges during a $1 \mathrm{sec}$ seizure period) was averaged manually for $5 \mathrm{~min}$ according to the different time periods studied. Propagation of this epileptiform activity to other areas was also analyzed.

\section{Behavioral study}

Animal behavior was scored by continuous observation before, during and after vehicle or drug administration, using a modified version of the Racine scale [23]. Briefly, behavior was scored as follows: 0, behavioral arrest (motionless), piloerection, excitement and rapid breathing; 1, movement of the mouth, lips tongue and vibrissae, salivation; 2 , head and eye clonus; 3 , forelimb clonus, "wet dog shakes"; 4, clonic rearing; 5, clonic rearing with loss of postural control and uncontrolled jumping.

\section{Perfusion and Immunofluorescence}

Rats were anaesthetized with nembutal $(60 \mathrm{mg} / \mathrm{kg}$, i.p.) and transcardially perfused with phosphate buffer saline

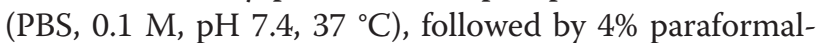
dehyde (in 0.1 M PBS, pH 7.4) containing $0.1 \%$ glutaraldehyde. The animal's brain was removed and post-fixed for 12 to $16 \mathrm{~h}$ at $4{ }^{\circ} \mathrm{C}$. The brains were then mounted on a vibratome (Leica, VT1000S, Germany) and sliced coronally at a thickness of $50 \mu \mathrm{m}$. These sections were collected consecutively in separate wells of an incubation chamber containing PBS.

Antibodies directed against the EAAT-3 glutamate transporter (rabbit polyclonal antiserum, c-terminal amino acids 455-524 of human EAAT-3: Santa Cruz Biotechnology, Inc., Santa Cruz, CA) and the GAT-1 GABA transporter (rabbit polyclonal antiserum, c-terminal amino acids 588-599 of rat GAT-1: Chemicon International, Temecula, CA) were used. A monoclonal NeuN antiserum (Chemicon International) was used to identify neurons.

Immunofluorescence was performed as described previously [25]. Briefly, EAAT-3 and GAT-1 immunofluorescence was performed using PBS and TRIS-buffer saline (TBS; $0.1 \mathrm{M}, \mathrm{pH} 7.4$ ), respectively, in conjunction with the NeuN antibody. Tissue sections were washed twice for 15 min in PBS or TBS with agitation and they were then incubated for $2 \mathrm{~h}$ at room temperature with 5\% normal goat serum (NGS) in PBS or TBS. After two $15 \mathrm{~min}$ washes, the sections were incubated for $72 \mathrm{~h}$ at $2-8^{\circ} \mathrm{C}$ with combinations of the primary antibodies (anti-EAAT-3, 1:500; anti-GAT1, 1:250; and anti-NeuN, 1:1000) diluted in PBS or TBS containing 5\% NGS and $0.3 \%$ Triton X-100. The sections were then washed five times with agitation for $10 \mathrm{~min}$ in PBS or TBS and incubated with the secondary antibody with agitation for $2 \mathrm{~h}$ in darkness at room temperature. EAAT-3 and GAT1 were detected using goat anti-rabbit IgG-Alexa 594 (1:500: Invitrogen, Oregon, USA) in PBS or TBS containing 5\% NGS, respectively, while NeuN was identified using a goat anti-mouse IgG-Alexa 488 (1:500: Invitrogen, Oregon, USA). Sections were washed five times with agitation for 15 min each in PBS or TBS $[8,18]$ before mounting on glass slides and coverslipping using vectashield to preserve fluorescence. The sections were examined by fluorescence microscopy (Olympus, U-LH100HG, Japan) and analyzed using Photoshop CS4 software. Control sections were incubated without primary antibody or by replacing the primary antibody with normal rabbit serum, and no fluorescent signal was observed in any of the control sections (data not shown).

\section{Cell counting}

As described previously [25], the number of cells was calculated by manual observation of fluorescence microscopy images using Photoshop CS4 software (Version 11.0). Cells of the DG or CA1 region of the hippocampus were counted in merged images of double-labelled sections (EAAT-3/ NeuN or GAT-1/NeuN) using a 40x objective (5 images for each transporter in each animal). Counting was restricted to a defined area of tissue (DG or CA1) using a modification of West's method [26]. Briefly, a number of slices at uniform intervals were selected from the total number of slices obtained per region $(5$ slices were selected from a total of 10 per animal) and the total number of co-labelled neurons in the DG or CA1 was counted using an optical dissector (height $=0.01 \mathrm{~mm}$ ). This systematic scanning was performed in $50 \mu \mathrm{m}$ slices over a defined region of interest with an area of $35,200 \mu \mathrm{m}^{2}$ (based on the objective used and the image area captured). The number of cells counted in the optical dissector was then corrected according to the counting area, the proportion of the slices analysed (50\%) and the thickness of the slice, providing a total value for the region of interest.

\section{Histological evaluation}

To verify the location of the guide cannula in each experiment, some coronal brain sections (50 mm thick) were taken from rats previously perfused to immunofluorescence and belonging to different experimental and control groups, then stained with cresyl violet and if the cannula was implanted incorrectly the animals were excluded from the study. 


\section{Data analysis}

Comparative analysis of the experimental and control groups was performed using a one-way analysis of variance (ANOVA) and a Tukey-Kramer post hoc test. A paired Student's $t$ test was used to compare control and experimental groups at equivalent time points. The Mtab13 statistical software package was used for all analyses. Results were considered statistically significant at $\mathrm{p}<0.05$.

\section{Results}

EEG activity and seizure behavior in animals

In vehicle-treated animals, EEG activity was characterized by the presence of slow physiological waves of low amplitude and frequency, similar to the basal EEG activity in the animals administered 4-AP (Figures 1 and 2). No convulsive behavior was observed in the control animals that received the vehicle alone, and they displayed only sporadic tidying and scratching behavior before and after
$\mathrm{NaCl}$ administration. 4-AP administration to the $\mathrm{rEC}(\mathrm{n}=$ 15) induced epileptiform activity, which was characterized by the presence of trains of poly-spikes and low amplitude and frequency spike-wave complexes that became more intense during the course of the experiment. The first epileptiform discharge was observed in the $\mathrm{rEC}(134 \pm 86.4 \mathrm{~s})$, and then in the $10 C(151 \pm 79.5 \mathrm{~s}), \operatorname{lOCB}(263 \pm 136 \mathrm{~s})$ and finally in the rOC $(266 \pm 136 \mathrm{~s})$.

The maximum amplitude and frequency of epileptiform activity was observed between 30 and 60 min after 4-AP administration in animals sacrificed at $180 \mathrm{~min}$, and it was associated with a score of 3-4 on the modified Racine Scale [23] (Table 1). In this experimental group, epileptiform activity decreased in amplitude, particularly between 90 and $120 \mathrm{~min}$ after 4-AP administration, returning to basal levels $180 \mathrm{~min}$ after 4-AP administration (Figures 1 and 2). These animals received scores of 1,2 or 3 on the modified Racine scale at the end of experiment.

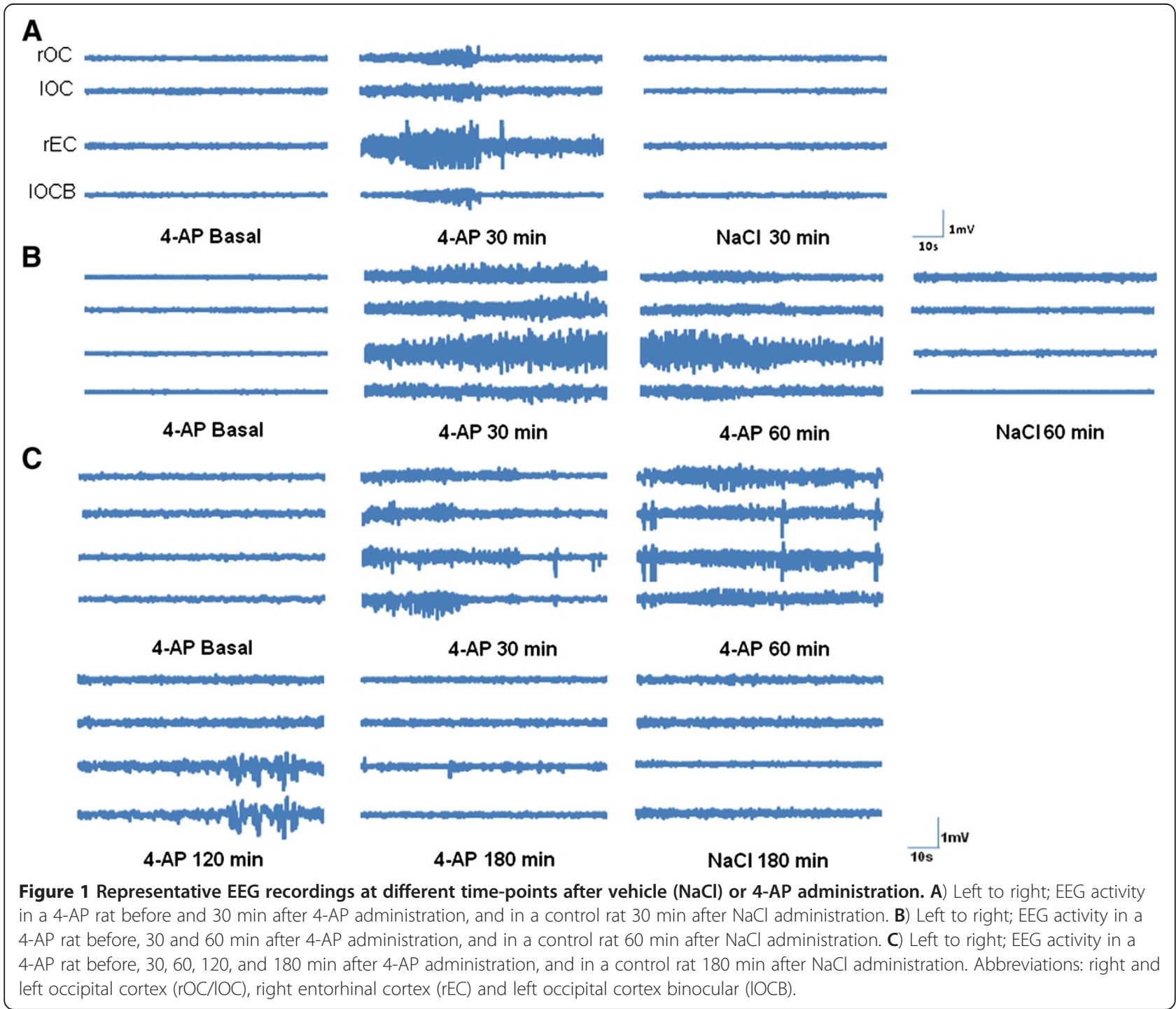




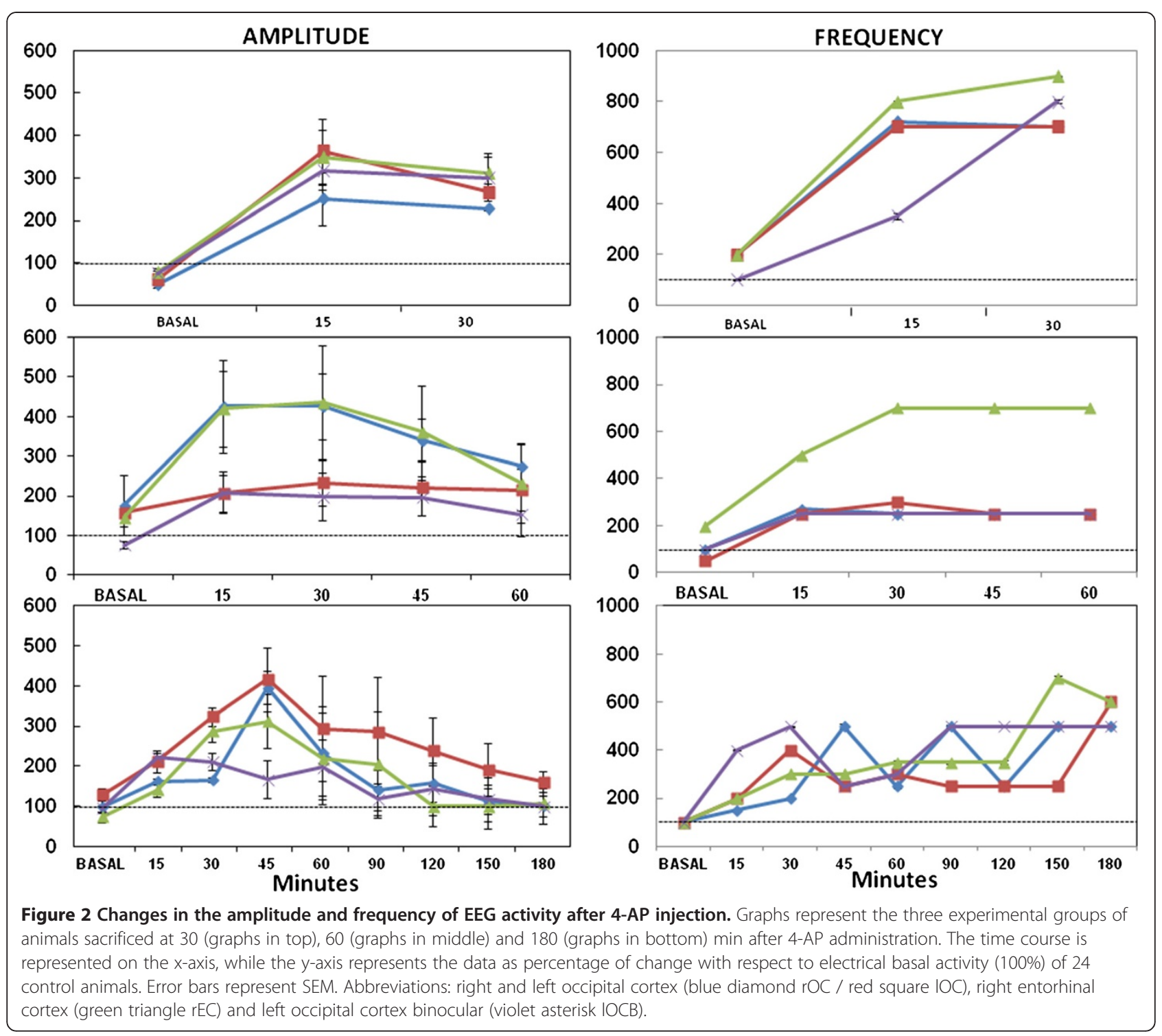

Effect of 4-AP on EAAT-3 colabelling

EAAT-3 labeling was observed around the soma and dendrites of granule cells in the DG and pyramidal cells in the CA region, both in control and experimental animals (Figure 3). There were no significant differences in the number in EAAT-3/NeuN dual labeled cells observed in experimental and control animals sacrificed $30 \mathrm{~min}$ after injection (Figure 4). However, more EAAT-3/NeuN dual labeled cells were evident in the DG of animals sacrificed 60 min post 4-AP injection than in control animals (right DG (rDG), $2931 \pm 52$ vs. $2457 \pm 178$; left DG (IDG), 2980 \pm 14 vs. $2253 \pm 42$ co-labeled cells $\left./ \mathrm{mm}^{3}, \mathrm{p}<0.001\right)$ that represent $19 \%$ and $32 \%$ of change in the rDG and IDG, respectively. In parallel, we observed a decrease in the number of EAAT-3/NeuN co-labeled cells in the CA1 of 4-AP-treated animals when compared with controls (right
CA1 (rCA1), $1145 \pm 18$ vs.1327 \pm 31; left CA1 (lCA1), $1059 \pm 16$ vs. $1217 \pm 21$ co-labeled cells $\left./ \mathrm{mm}^{3}, \mathrm{p}<0.001\right)$, this is $14 \%$ and $13 \%$ of change in the rCA 1 and lCA1, respectively. In animals sacrificed $180 \mathrm{~min}$ after 4-AP injection, the number of CA1 pyramidal cells expressing EAAT3 decreased when compared with the control animals $(\mathrm{rCA} 1,927 \pm 14$ vs. $992 \pm 23$; lCA1, $915 \pm 11$ vs. $956 \pm 17$ co-labeled cells $\left./ \mathrm{mm}^{3}, \mathrm{p}<0.05\right)$, that represent $7 \%$ of change in $\mathrm{rCA} 1$ and $5 \%$ in $\mathrm{lCA} 1$. By contrast, no significant changes were observed in the DG region.

\section{Effect of 4-AP on GAT-1 colabelling}

GAT-1 labeling was observed around the soma of granule cells in the DG and pyramidal cells in CA1, both in control and 4-AP-treated animals (Figure 3). No significant changes in GAT-1/NeuN colabelling were observed in either region 


\section{Table 1 Seizure behavior of the three groups of rats following intra-rEC administration of 4-AP (10 $\mathrm{nmol}, \mathrm{n}=\mathbf{5}$ per group)}

\begin{tabular}{lllllll}
\hline \multicolumn{6}{c}{ Behavior after 4 AP Injection } \\
\hline RAT & \multicolumn{6}{l}{ Minutes } \\
\cline { 2 - 7 } & $\mathbf{1 5}$ & $\mathbf{3 0}$ & $\mathbf{4 5}$ & $\mathbf{6 0}$ & $\mathbf{1 2 0}$ & $\mathbf{1 8 0}$ \\
\hline $\mathbf{1 - 5}$ (A) & $0 / 1 / 2 / 3$ & $0 / 1 / 2 / 3$ & & & & \\
$\mathbf{6 - 1 0}$ (B) & $0 / 1 / 2$ & $0 / 1 / 2 / 3 / 4$ & $0 / 1 / 2 / 3 / 4$ & $0 / 1 / 2 / 3$ & & \\
$\mathbf{1 1 - 1 5}$ (C) & $0 / 1 / 2 / 3$ & $1 / 2 / 3 / 4$ & $0 / 1 / 2 / 3 / 4$ & $0 / 1 / 2 / 3 / 4$ & $0 / 1 / 2 / 3$ & $0 / 1 / 2 / 3$
\end{tabular}

The values represent seizure behavior according to the modified Racine Scale [23]: 0, behavioral arrest (motionless), piloerection, excitement and rapid breathing; 1 , movement of the mouth, lips tongue and vibrissae, salivation; 2 head clonus and eye clonus; 3 , forelimb clonus, "wet dog shakes"; 4 , clonic rearing; 5 , clonic rearing with loss of postural control and uncontrolled jumping.

The rats were sacrificed $30(\mathrm{~A}), 60(\mathrm{~B})$ or $180(\mathrm{C})$ min after 4-AP injection

between control and 4-AP-treated animals sacrificed at 30 min (Figure 4). However, 60 min after 4-AP administration we observed an increase in the number of GAT-1 labeled cells in the DG and CA1 when compared with vehicle-treated animals (rDG, $2656 \pm 36$ vs. $2364 \pm 42$; IDG, $2949 \pm 24$ vs. $2058 \pm 44$; rCA1, $1155 \pm 23$ vs. 1055 \pm 6; lCA1 $1090 \pm 11$ vs. $1032 \pm 10$ co-labeled cell $/ \mathrm{mm}^{3}$, $\mathrm{p}<0.05$ ), this is $12 \%$ and $43 \%$ of change in rDG and IDG, respectively, while in rCA1 and ICA1 was observed 9\% and $5 \%$ of change. In animals sacrificed 180 min after 4-AP injection, the number of GAT-1 labeled cells in the DG decreased when compared with vehicle-treated animals (rDG, $2270 \pm 19$ vs. $2329 \pm 8$; lDG, $2224 \pm 60$ vs. $2468 \pm 87$ co-labeled cells $/ \mathrm{mm}^{3}, \mathrm{p}<0.05$ ), that represent $3 \%$ and $10 \%$ of change in rDG and IDG, respectively, while there were no changes in GAT-1 in the CA1.

\section{Discussion}

Local administration of 4-AP into the rEC induced epileptiform activity characterized by poly-spike trains and spikewave complexes, peaking between 30 and $60 \mathrm{~min}$ after 4-AP administration, and consistent with previous studies in our laboratory $[23,24]$. Moreover, the maximal EEG activity coincided with convulsive behavior that was associated with a score of $3 / 4$ on the modified Racine Scale [23]. Epileptiform discharges were first detected in the $\mathrm{rEC}$, followed by the $1 O C$ and $\mathrm{OOCB}$, and finally in the rOC.

EAAT-3 colabelling was detected in the soma and dendrites of dentate granule cells and pyramidal cells of control groups. In agreement with our study, Holmseth et al. [27] detected EAAT-3 labeling intracellularly in soma and dendrites in DG of hippocampus, they estimated the mean EAAT-3 density (90 molecules $\left./ \mu \mathrm{m}^{2}\right)$ in dendritic membrane but the most of the EAAT-3 was located intracellularly assuming that EAAT-3 is evenly distributed. Animals sacrificed $30 \mathrm{~min}$ after 4-AP administration exhibited no changes in the average number of cells immunolabelled for EAAT-3 or GAT-1, in either the CA1 or DG. However,
60 min after 4-AP-induced epileptiform activity, the number of EAAT-3/NeuN co-labeled cells increased bilaterally in the DG while decreased in CA1. The present findings are supported by early studies describing decreased EAAT3 immunolabeling in rat pyramidal cells of CA1 just $4 \mathrm{~h}$ after seizure onset produced by kainic acid administration [28]. Increased EAAT-3 immunoreactivity (IR) in granule cells of DG during the acute epileptic phase (24 h) was observed in the animal model of status epilepticus (SE) induced by electrical stimulation [29], and increases in EAAT-3 and GAT-1 IR have been described in granular and pyramidal cells of hippocampal sections from TLE patients $[13,14]$. Although, these last data cannot be directly compared with the present results, all these findings indicate important changes in expression of EAAT-3 transporter during seizures and epilepsy. The decreases in CA1 EAAT-3 labeled cells described here contrast with the increases in EAAT-3 IR neurons in the CA1-3 of animals with SE reported previously [29]. This discrepancy may be due to differences in the protocols used to induce seizures, in the EAAT-3 antibodies used and in the time between seizure induction and tissue processing, further increasing the potential divergence in the results.

CA1 and CA3 neurons have already been described to be more susceptible to seizures than those in other CA regions [30,31] and neuronal damage in CA1/CA3 was observed after 4-AP injection in hippocampus [32] that contrast with abundant NMDA receptors found in this region [33], similarly antagonists to this receptor protects against seizures and damage $[34,35]$. These early studies support our results about decreased EAAT-3 labeled cells observed in CA1. Indeed, kainic acid administration decreases EAAT-3 IR and EAAT-3 mRNA expression in CA1 pyramidal cells [28]. Together, these findings suggest a rapid down regulation of EAAT-3 transporter expression in the CA1 during seizures.

Considering that only $20-30 \%$ of EAAT-3 is localized at the plasma membrane [36,37] and the intracellular EAAT3 can be inserted rapidly into the plasma membrane in response to activity or pathological conditions like seizures $[36,38,39]$, the increase of EAAT-3 in soma of granule cells found $60 \mathrm{~min}$ after seizures induced by 4-AP could function as a available pool of EAAT-3 for redistribution to the plasma membrane to facilitates the capture as well as the clearance of glutamate excess from the extrasynaptic space, particularly given the localization of EAAT-3 transporters in asymmetrical and symmetrical synapses in the soma and dendrites of granule cells $[8,10]$. This hypothesis is supported by our previous studies where an increase in extracellular glutamate levels (up 400\% of change with respect to the baseline) in hippocampus was observed during the first epileptiform discharge after 4-AP (10 nmol) injection into the $\mathrm{EC}$, these increases in glutamate levels were decreased as the seizure progress and at $60 \mathrm{~min}$ after 4-AP administration, glutamate concentrations were returned to 


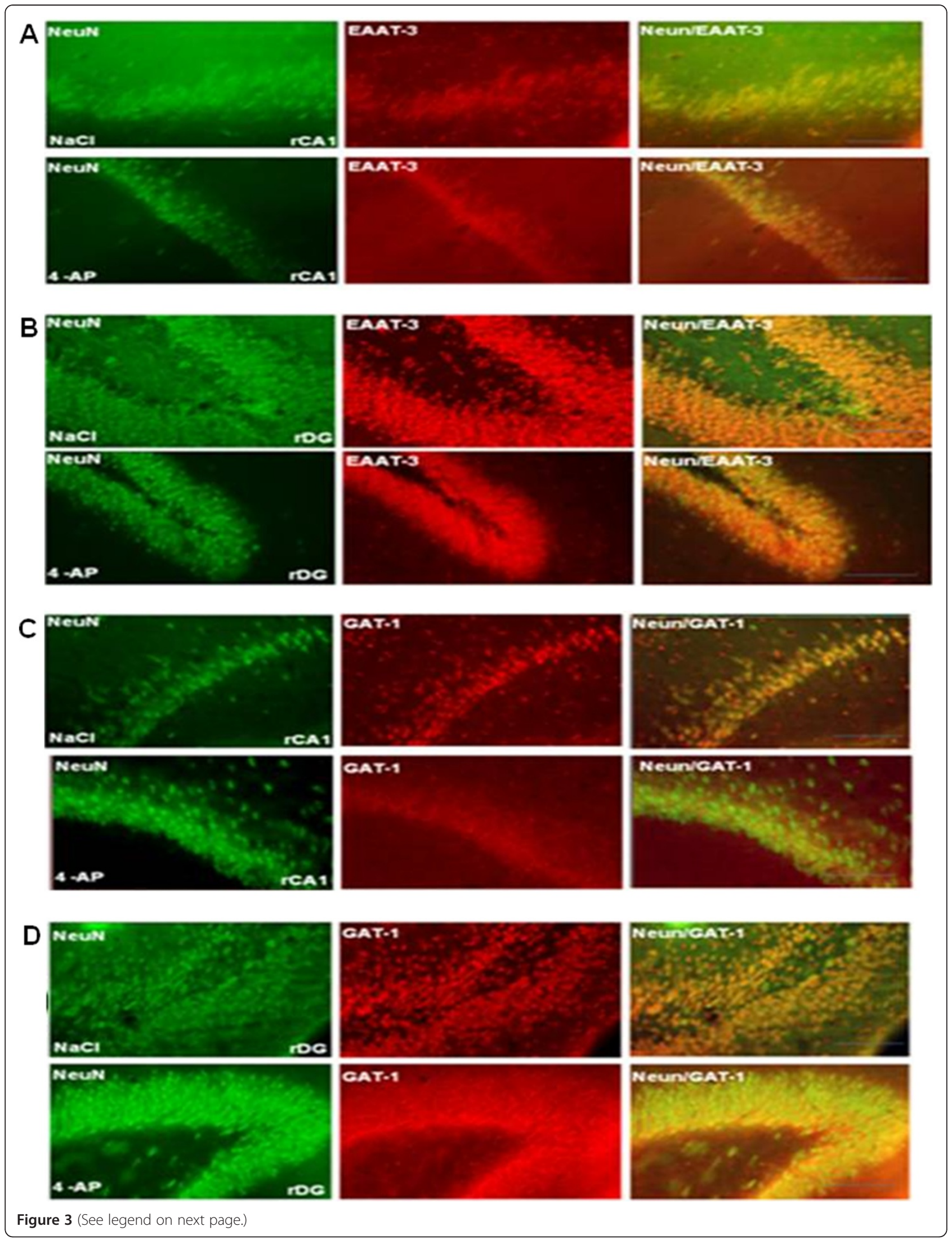


(See figure on previous page.)

Figure 3 Representative fluorescence microscopy images obtained from control and experimental animals where it is observed NeuN, EAAT-3 or GAT-1 labeled cells, as well as co-labeled cells (NeuN/EAAT-3 or NeuN/GAT-1) in various brain regions: A and C) in right CA1 (rCA1); B and D) in right dentate gyrus (rDG). Scale bar $=50 \mu \mathrm{m}$.

basal condition, this temporal profile agree with the results obtained here $[4,40]$. In addition, the methodologies used in these studies (an electrochemical biosensor and enzymatic reactor with electrochemical detection) allowed us to improve time resolution of about 1 min per microdialysis sample $[4,40]$. Also, co-expression of the NMDA glutamate receptor with the EAAT-3 transporter in Xenopus oocytes decreases the activation of the former [41], suggesting a protective role of the EAAT-3 transporter in excitotoxic conditions and in co-operation with the cysteine/glutamate antiporter $\mathrm{X}_{\mathrm{c}}^{-}$, the EAAT-3 transporter helps to protect neuronal HT22 cells (an immortalized hippocampal cell line) from oxidative glutamate toxicity [11]. Increases in
EAAT-3/NeuN colabelling in dentate granular cells may also enhance inhibitory activity by increasing GABA synthesis. In agreement, the GAD/GABA markers in granule cells are transiently up-regulated in response to seizures $[42,43]$. The EAAT-3 transporter also participates in the rapid adaptation of pre-synaptic inhibitory terminals to alterations in local network activity by replenishing vesicular glutamate content, which can then be converted to GABA for release $[44,45]$. Furthermore, kindled seizures induce GABAergic fast synaptic inhibition in the mossy fibers of the DG to CA3 system [46].

Animals sacrificed $180 \mathrm{~min}$ after 4-AP injection exhibited bilateral decreases in the average number of EAAT-3/NeuN

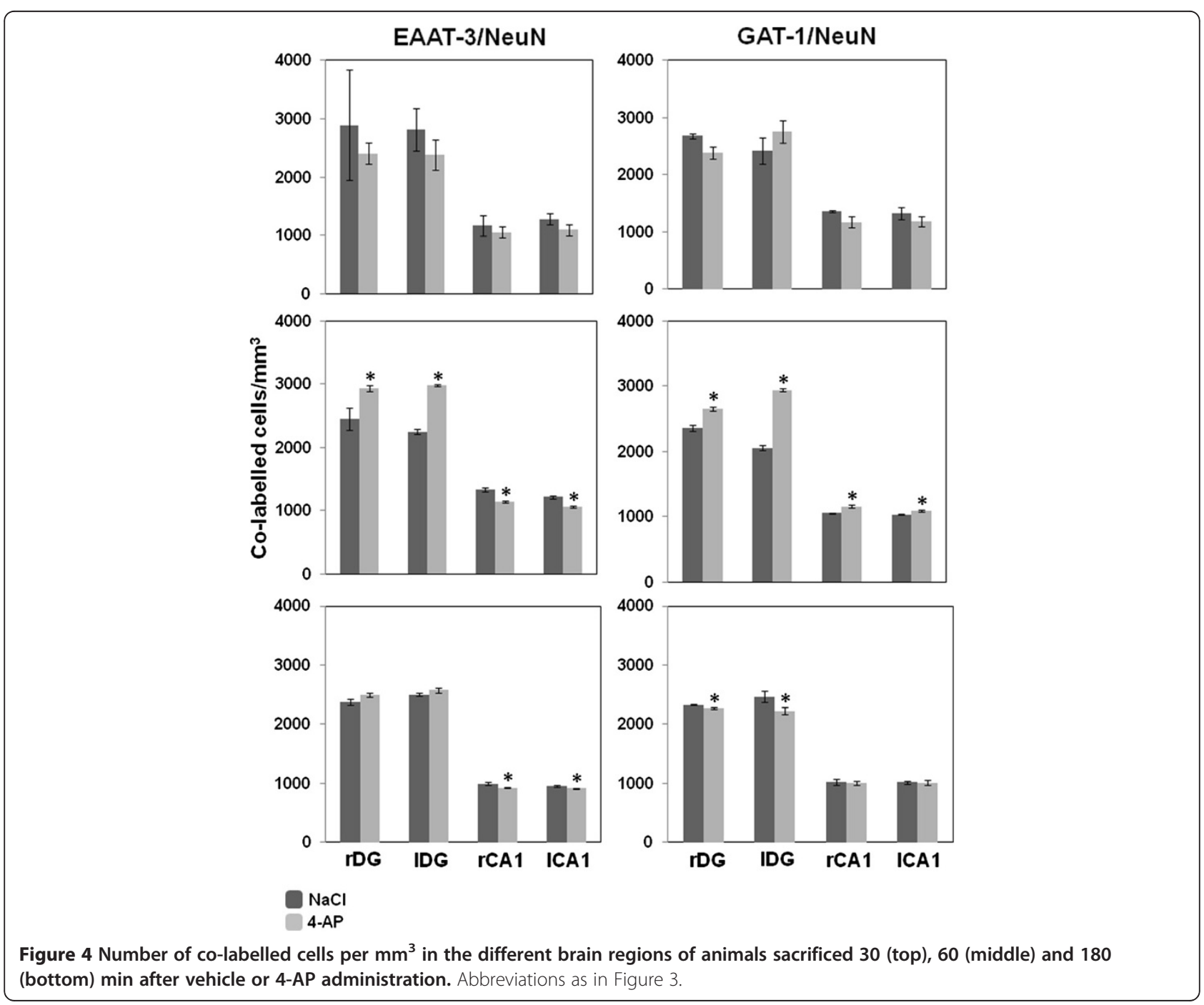


co-labeled pyramidal cells in the CA1. Decreased EAAT-3 IR was also described previously in rat CA1 pyramidal cells 4 hours after KA treatment [28] and diminished EAAT-3 mRNA expression was reported in the rat hippocampus $4 \mathrm{~h}$ after ferric chloride treatment [47]. Taken together, these results suggest a rapid down regulation of EAAT-3 transporter during seizures induced by diverse chemical agents. The decrease in the average number of EAAT-3/NeuN colabeled pyramidal cells from 60 to $180 \mathrm{~min}$ after 4-AP administration supports the hypothesis that CA1 neurons are highly susceptible to seizures. However, decreased EAAT-3 transporter expression can induce seizures, as seen when using an anti-sense oligopeptide antibody to EAAT-3 [48].

In the present study, maximum seizure intensity and convulsive behavior elicited by a low dose of 4-AP (10 nmols) was correlated with a rapid up-regulation of EAAT-3/NeuN colabelling $60 \mathrm{~min}$ after 4-AP injection. It is established that 4-AP increase extracellular levels of glutamate that originate from pre-synaptic nerve endings to produce an overactivation of glutamate receptors and subsequent seizures as well as neurodegeneration of the CA1, CA2 and CA3 hippocampal subfields [2,3] This effect is blocked by glutamate receptor antagonists of both the NMDA and the non-NMDA types in vivo as in vitro experiments [34,49]. Also it is known that CA1 contains a high expression of NMDA receptors [50]. EAAT-3 as a neuronal transporter, not only to uptake glutamate from synaptic cleft to maintain of low extracellular glutamate, also it contributes to multiple aspects of synaptic signaling: EAAT-3 limits glutamate spillover and participates to neuronal uptake of cysteine, a critical precursor for glutathione synthesis and importantly EAAT-3 can attenuate the activation of perysinaptic NMDA receptors [41,51]. With base in these arguments and as an effect caused by 4-AP, the increase in EAAT-3 colabelled cells in DG after $60 \mathrm{~min}$ postseizures induced by 4-AP could function as an available pool of EAAT-3 for redistribution to the plasma membrane to facilitate the capture as well as the clearance of glutamate excess from the extrasynaptic space to attenuate the overactivation of perysinaptic NMDA receptors. This compensatory mechanism has the purpose to attenuate seizures and the associated convulsive behavior; these latter effects were observed 180 min after 4-AP injection (Figure 1C, 2 and Table 1).

GAT-1 colabelling was detected in the soma and dendrites of dentate granule cells and pyramidal cells, in agreement with previous studies [20,52]. Bilateral increases in the number of GAT-1/NeuN co-labeled cells in the DG and CA1 were observed in this study. These results are related with significant increases of GAT-1 mRNA found bilaterally in the hippocampal DG at $1 \mathrm{~h}$ after kindled generalized seizures [53]. In addition, this up-regulation of GAT-1/NeuN colabelling observed 60 min after 4-AP administration may augment GABA release into the synaptic cleft via reverse transport, counteracting the excitatory activity produced by glutamate release induced by 4-AP.
This hypothesis is supported by the following experimental evidences. Reverse transport via GAT-1 transporters has been described in cultured hippocampal neurons, where it facilitates phasic inhibition through the activation of GABA-A receptors in both normal and pathological conditions [54,55]. GAT-1 reverse transport and activation of nearby GABA receptors have also been reported in glia $[55,56]$. Given the dual role of granule cells in GABA and glutamate neurotransmission during seizures [46] reverse transport via GAT-1 may increase GABA release from dentate granule cells, thereby reducing hyperactivity and seizure activity in this region. In addition, previous studies have demonstrated that 4-AP increase GABA levels in hippocampus at different 4-AP concentrations during and after 4-AP administration [22,57]. However, it is necessary additional experimental work using a high time resolution methodology to confirm a better relation between GABA levels, EEG activity and GAT-1 labeling throughout seizures induced by 4-AP. Finally, we observed a decrease in GAT-1/NeuN colabelling in dentate granule cells $180 \mathrm{~min}$ after seizure induction, which was accompanied by a decrease in seizure activity. Although, we cannot compare the decrease of GAT-1 observed 180 min after 4-AP treatment with other studies, since there are not available data in this matter, we could suggest that the rapid upregulation of GAT-1 labeled cells seen in the DG and CA1 at $60 \mathrm{~min}$ was sufficient to abolish epileptiform discharges in these regions as well as the seizure behavior of animals observed $180 \mathrm{~min}$ after 4-AP.

\section{Conclusion}

Our results provide evidence that the average number of cells immunolabelled for EAAT-3 is rapidly up-regulated in dentate granule cells during acute seizures. We propose that this represents a protective and compensatory adaptation to enabling more rapid and efficient removal of glutamate from the extrasynaptic space induced by 4-AP and thus attenuating seizure activity. The increase in EAAT-3/ NeuN colabelling may also enhance inhibitory activity in dentate granule cells by increasing GABA synthesis, further counteracting the hyperexcitation of glutamate. Also, our results reveal a high degree of seizure susceptibility in CA1 pyramidal cells, as demonstrated by a decrease in EAAT-3 expression in this region. Finally, the increase in GAT-1/ NeuN colabelling observed in DG cells may facilitate increased GABA release in this region via reverse transport, further attenuating seizure activity, but it is necessary additional experimental work to confirm this hypothesis. Together, these findings contribute to our understanding of the role of glutamate and GABA transporters in acute seizures particularly induced by 4-AP.

\section{Competing interests}

The authors have no competing interests. 


\section{Authors' contributions}

LMC participated in supervising experiments, analysis and discussion of results, manuscript preparation and final revision; FSG contributed in experiments and analysis of results; AMV and SJLP contributed in discussion of results and final revision. All authors read and approved the final manuscript.

\section{Acknowledgements}

This study was supported by the grants from LMC, COECYTJAL-U. de G. (PS2009-489 and 558), CONACYT-SEP-CB 106179 and from AMV, CONACYT-SEPCB 105807. We wish to thank Dr. Graciela Gudiño-Cabrera for her assistance with the fluorescence microscopy.

Received: 4 April 2012 Accepted: 21 August 2012

Published: 29 August 2012

\section{References}

1. Angus-Leppan H, Parsons LM: Epilepsy: epidemiology, classification and natural history. Medicine 2008, 11:571-578.

2. Medina-Ceja L, Morales-Villagrán A, Tapia R: Action of 4-aminopyridine on extracellular amino acids in hippocampus and entorhinal cortex: a dual microdialysis and electroencephalographic study in awake rats. Brain Res Bull 2000, 53:255-262.

3. Tapia R, Medina-Ceja L, Peña F: On the relationship between extracellular glutamate, hyperexcitation and neurodegeneration, in vivo. Neurochem Int 1999, 34:23-31.

4. Morales-Villagrán A, Medina-Ceja L, López-Pérez SJ: Simultaneous glutamate and EEG activity measurements during seizures in rat hippocampal región with the use of an electrochemical biosensor. J Neurosci Methods 2008, 168:48-53.

5. Lauriat TL, Mclnnes LA: EAAT-2 regulation and splicing: relevance to psychiatric and neurological disorders. Mol Psychiatry 2007, 12:1065-1078.

6. Medina-Ceja L, Guerrero-Cazares H, Canales-Aguirre A, Morales-Villagran A Feria-Velasco A: Structural and functional characteristics of glutamate transporters: how they are related to epilepsy and oxidative stress. Rev Neurol 2007, 45:341-352.

7. Melone M, Bellesi M, Ducati A, Lacoangeli M, Conti F: Cellular and synaptic localization of EAAT2a in human cerebral cortex. Front Neuroanat 2011 4:151.

8. Furuta A, Martin LJ, Lin CL, Dykes-Hoberg M, Rothstein JD: Cellular and synaptic localization of the neuronal glutamate transporters excitatory amino acid transporter 3 and 4. Neuroscience 1997, 81:1031-1042.

9. Maragakis NJ, Rothstein JD: Glutamate transporters in neurologic disease. Arch Neurol 2001, 58:365-370.

10. Rothstein JD, Martin L, Levey Al, Dykes-Hoberg M, Jin L, Wu D, Nash N Kuncl RW: Localization of neuronal and glial glutamate transporters. Neuron 1994, 13:713-725

11. Lewerenz J, Klein M, Methner A: Cooperative action of glutamate transporters and cystine/glutamate antiporter system Xc- protects from oxidative glutamate toxicity. J Neurochem 2006, 98:916-925.

12. Crino PB, Jin H, Shumate MD, Robinson MB, Coulter DA, Brooks-Kayal AR Increased Expression of the Neuronal Glutamate Transporter (EAAT3/ EAAC1) in Hippocampal and Neocortical Epilepsy. Epilepsia 2002, 43: 211-218.

13. Mathern GW, Mendoza D, Lozada A, Peerorius JK, Dehnes Y, Danbolt NC, Nelson N, Leite JP, Chimelli L, Born DE, Sakamoto AC, Assirati JA, Fried I, Peacock WJ, Ojemann GA, Adelson PD: Hippocampal GABA and glutamate transporter immunoreactivity in patients with temporal lobe epilepsy. Neurology 1999, 52:453-472.

14. Proper EA, Hoogland G, Kappen SM, Jansen GH, Rensen MG, Schrama LH, van Veelen CW, van Rijen PC, van Nieuwenhuizen O, Gispen WH, de Graan PN: Distribution of glutamate transporters in the hippocampus of patients with pharmaco-resistant temporal lobe epilepsy. Brain 2002, 125:32-43.

15. Zhang G, Raol YSH, Hsu F-C, Brooks-Kayal AR: Long-term alterations in glutamate receptor and transporter expression following early-life seizures are associated with increased seizure susceptibility. J Neurochem 2004, 88:91-101.

16. Ueda Y, Willmore L: Hippocampal gamma-aminobutyric acid transporter alterations following focal epileptogenesis induced in rat amygdala. Brain Res Bull 2000, 52:357-361.
17. Sarup A, Larsson OM, Schousboe A: GABA transporters and GABAtransaminase as drug targets. Curr Drug Targets CNS Neurol Disord 2003, 2:269-277.

18. Yan XX, Carriaga WA, Ribak CE: Immunoreactivity for GABA plasma membrane transporter, GAT-1, in the developing rat cerebral cortex: transient presence in the somata of neocortical and hippocampal neurons. Develop Brain Res 1997, 99:1-19.

19. Jiang KW, Gao F, Shui QX, Yu ZS, Xia ZZ: Effect of diazoxide on regulation of vesicular and plasma membrane GABA transporter genes and proteins in hippocampus of rats subjected to picrotoxin-induced kindling. Neurosci Res 2004, 50:319-329.

20. Lee TS, Bjornsen LP, Paz C, Kim JH, Spencer SS, Spencer DD, Eid T, de Lanerolle NC: GAT-1 and GAT-3 expression are differently localized in the human epileptigenic hippocampus. Acta Neuropathol 2006, 111:351-363.

21. Sperk G, Schwarzer C, Heilman J, Furtinger S, Reimer RJ, Edwards RH, Nelson $\mathrm{N}$ : Expression of plasma membrane GABA transporters but not of the vesicular GABA transporter in dentate granule cells after kainic acid seizures. Hippocampus 2003, 13:806-15.

22. Peña F, Tapia R: Relationships among seizures, extracellular amino acids changes, and neurodegeneration induced by 4 -aminopyridine in rat hippocampus: A microdialysis and electroencephalographic study. J Neurochem 1999, 72:2006-2014.

23. Medina-Ceja L, Cordero-Romero A, Morales-Villagrán A: Antiepileptic effect of carbenoxolone on seizures induced by 4-aminopyridine: A study in the rat hippocampus and entorhinal cortex. Brain Res 2008, 1187:74-81.

24. Medina-Ceja L, Ventura-Mejía C: Differential effects of trimethylamine and quinine on seizures induced by 4-aminopyridine administration in the entorhinal cortex of vigilant rats. Seizure 2010, 19:507-513.

25. Medina-Ceja L, Sandoval-García F, Pardo-Peña K: Effect of early glutamate exposure on EAAT-3 and GAT-1 protein expression in cells of the dentate gyrus and CA1 region of the Adult Rat Hippocampus. Arch Med Res 2011, 42:433-438.

26. West MJ: New Stereological methods for counting neurons. Neurobiol Aging 1993, 14:275-285.

27. Holmseth S, Dehnes Y, Huang YH, Follin-Arbelet W, Grutle NJ, Mylonakou MN, Plachez C, Zhou Y, Furness DN, Bergles DE, Lehre KP, Danbolt NC: The density of EAAC1 (EAAT3) glutamate transporters expressed by neurons in the mammalian CNS. J Neurosci 2012, 32:6000-6013.

28. Simantov R, Crispino M, Hoe W, Broutman G, Tocco G, Rothstein JD, Baudry $\mathrm{M}$ : Changes in expression of neuronal and glial glutamate transporters in rat hippocampus following kainate-induced seizure activity. Brain Res Mol Brain Res 1999, 65:112-123.

29. Gorter JA, Van Vliet EA, Proper EA, De Gran PN, Ghijsen WE, Lopes Da Silva $\mathrm{FH}$, Aronica E: Glutamate transporters alterations in the reorganizing dentate gyrus are associated with progressive seizure activity in chronic epileptic rats. J Comp Neurol 2002, 442:365-377.

30. Hanaya R, Sasa M, Sugata S, Tokudome M, Serikawa T, Kurisu K, Arita K Hippocampal cell loss and propagation of abnormal discharges accompanied with the expression of tonic convulsion in the spontaneously epileptic rat. Brain Res 2010, 1328:171-180.

31. Qian J, Xu K, Yoo J, Chen TT. Andrews G, Noebels JL: Knockout of Zn transporters Zip-1 and Zip-3 attenuates seizure-induced CA1 neurodegeneration. J Neuroci 2011, 31:97-104.

32. Peña $F$, Tapia R: Seizures and neurodegeneration induced by 4-aminopyridine in rat hippocampus in vivo: Role of glutamate, and GABA mediated neurotransmition and of ion channels. Neuroscience 2000, 101:547-561.

33. Sakurai SY, Cha JH, Penney JB, Young AB: Regional distribution and properties of [3 H]MK-801 binding sites determined by quantitative autoradiography in rat brain. Neuroscience 1991, 40:533-543.

34. Morales-Villagrán A, Ureña-Guerrero M, Tapia R: Protection by NMDA receptor antagonists against seizures induced by intracerebral administration of 4-aminopyridine. Eur J Pharmacol 1996, 305:87-93.

35. Bagetta G, lannone M, Palma E, Nisticó G, Dolly JO: N-methyl-D-aspartate and non-N-methyl-D-aspartate receptors mediate seizures and CA1 hippocampal damage induced by dendrotoxin-K in rats. Neuroscience 1996, 71:613-624

36. Fournier KM, González MI, Robinson MB: Rapid trafficking of the neuronal glutamate transporter, EAAC1: evidence for distinct trafficking pathways differentially regulated by protein kinase $\mathrm{C}$ and platelet-derived growth factor. J Biol Chem 2004, 279:34505-34513. 
37. Sheldon Al, González MI, Robinson MB: A carboxyl-terminal determinant of the neuronal glutamate transporter, EAAC1, is required for plateletderived growth factor-dependent trafficking. J Biol Chem 2006, 281:4876-4886.

38. D’Amico A, Soragna A, Di Cairano E, Panzeri N, Anzai N, Vellea Sacchi F, Perego $C$ : The surface density of the glutamate transporter EAAC1 is controlled by interactions with PDZK1 and AP2 adaptor complexes. Traffic 2010, 11:1455-1470.

39. Ross JR, Porter BE, Buckley PT, Eberwine JH, Robinson MB: mRNA for the EAAC1 subtype of glutamate transporter is present in neuronal dendrites in vitro and dramatically increases in vivo after seizure. Neurochem Int 2011, 58:366-375.

40. Morales-Villagrán A, Sandoval-Salazar C, Medina-Ceja L: An analytical flow injection system to measure glutamate in microdialysis samples based on an enzymatic reaction and electrochemical detection. Neurochem Res 2008, 33:1592-1598.

41. Zuo Z, Fang $\mathrm{H}$ : Glutamate transporter type 3 attenuates the activation of $\mathrm{N}$-methyl-D-aspartate receptors co-expressed in Xenopus oocytes. J Exp Biol 2005, 208:2063-2070.

42. Schwarzer C, Sperk G: Hippocampal granule cells express glutamic acid decarboxylase-67 after limbic seizures in the rat. Neuroscience 1995, 69:705-709.

43. Sloviter RS, Dichter MA, Rachinsky TL, Dean E, Goodman JH, Sollas AL, Martin DL: Basal expression and induction of glutamate decarboxylase and GABA in excitatory granule cells of the rat and monkey hippocampal dentate gyrus. J Comp Neurol 1996, 373:593-618.

44. Mathews GC, Diamond JS: Neural glutamate uptake contributes to GABA synthesis and inhibitory synaptic strength. J Neurosci 2003, 23:2040-2048.

45. Sepkuty JP, Cohen AS, Eccles C, Rafiq A, Behar K, Ganel R, Coulter DA, Rothsein JD: A neuronal glutamate transporter contributes to neurotransmitter GABA synthesis and epilepsy. J Neurosci 2002, 22: 6372-6379.

46. Gutierrez R: Seizures induce simultaneous GABAergic and glutamatergic transmission in the dentate gyrus-CA3 system. J Neurophysiol 2000, 84:3088-3090

47. Doi T, Ueda $Y$, Tokumaru J, Mitsuyama $Y$, Willmore $L$ : Sequential changes in glutamate transporter mRNA levels during $\mathrm{Fe}^{3+}$-induced epileptogenesis. Mol Brain Res 2000, 75:105-112

48. Rothstein JD, Van Kammen M, Levey Al, Martin LJ, Kuncl RW: Selective loss of glial glutamate transporter GLT-1 in amyotrophic lateral sclerosis. Ann Neurol 1995, 38:73-84.

49. Siniscalchi A, Calabresi P, Mercuri NB, Bernardi G: Epileptiform discharge induced by 4-aminopyridine in magnesium-free medium in neocortical neurons: physiological and pharmacological characterization. Neuroscience 1997, 81:189-197.

50. Young AB, Sakurai SY, Albin RL, Makowiec R, Penney JB: Excitatory amino acid receptor distribution: quantitative autoradiographic studies. In Excitatory Amino Acids and Synaptic Transmission. Edited by Thompson AW. USA: Academic; 1991:19-31.

51. Scimemi A, Tian H, Diamond JS: Neuronal transporters regulate glutamate clearance, NMDA receptor activation, and synaptic plasticity in the hippocampus. J Neurosci 2009, 29:14581-14595.

52. Ribak CE, Tong WM, Brecha NC: GABA plasma membrane transporters, GAT-1 and GAT-3, display different distributions in the rat hippocampus. J Comp Neurol 1996, 367:595-606.

53. Hirao T, Morimoto K, Yamamoto Y, Watanabe T, Sato H, Sato K, Sato S, Yamada M, Tanaka K, Suwaki H: Time-dependent and regional expression of GABA transporter mRNAs following amygdala-kindled seizures in rats. Brain Res Mol Brain Res 1998, 54:49-55.

54. Wu Y, Wang W, Díez-Sampedro A, Richerson GB: Nonvesicular inhibitory neurotransmission via reversal of the GABA transporter GAT-1. Neuron 2007, 56:851-865.

55. Richerson GB, Yuanming W: Dynamic equilibrium of neurotransmitter transporters: not just for reuptake anymore. J Neurophisiol 2003, 90: 1363-1374.
56. Barakat L, Bordey A: GAT-1 and reversible GABA transport in Bergmann glia in slices. J Neurophysio/ 2002, 88:1407-1417.

57. Salazar P, Tapia R: Allopregnanolone potentiates the glutamate-mediated seizures induced by 4-aminopyridine in rat hippocampus in vivo. Neurochem Res 2012, 37:596-603.

doi:10.1186/1423-0127-19-78

Cite this article as: Medina-Ceja et al:: Rapid compensatory changes in the expression of EAAT-3 and GAT-1 transporters during seizures in cells of the CA1 and dentate gyrus. Journal of Biomedical Science 2012 19:78.

\section{Submit your next manuscript to BioMed Central and take full advantage of:}

- Convenient online submission

- Thorough peer review

- No space constraints or color figure charges

- Immediate publication on acceptance

- Inclusion in PubMed, CAS, Scopus and Google Scholar

- Research which is freely available for redistribution

Submit your manuscript at www.biomedcentral.com/submit
C BioMed Central 